\title{
Poly(N-Isopropylacrylamide) Surface-Grafted Chitosan Membranes as a New Substrate for Cell Sheet Engineering and Manipulation
}

\author{
Ricardo M.P. da Silva, ${ }^{1,2}$ Paula M. López-Pérez, ${ }^{1,2}$ Carlos Elvira, ${ }^{3}$ João F. Mano, ${ }^{1,2}$ Julio \\ San Román, ${ }^{1,2}$ Rui L. Reis ${ }^{1,2}$ \\ '3B's Research Group-Biomaterials, Biodegradables and Biomimetics, \\ Department of Polymer Engineering, University of Minho, Campus de Gualtar, \\ 4710-057 Braga, Portugal; telephone: +351 253604781; fax: +351 253604498; \\ e-mail: ricardosilva@dep.uminho.pt \\ ${ }^{2}$ IBB-Institute for Biotechnology and Bioengineering, PT Government Associated Laboratory, \\ Braga, Portugal \\ ${ }^{3}$ Department of Biomaterials, Institute of Polymer Science and Technology, CSIC, Juan de la \\ Cierva 3, 28006 Madrid, Spain
}

Received 13 March 2008; revision received 9 May 2008; accepted 22 May 2008

Published online 4 June 2008 in Wiley InterScience (www.interscience.wiley.com). DOI 10.1002/bit.22004

\begin{abstract}
The immobilization of poly $(N$-isopropylacrylamide) (PNIPAAm) on chitosan membranes was performed in order to render membranes with thermo-responsive surface properties. The aim was to create membranes suitable for cell culture and in which confluent cell sheets can be recovered by simply lowering the temperature. The chitosan membranes were immersed in a solution of the monomer that was polymerized via radical initiation. The composition of the polymerization reaction solvent, which was a mixture of a chitosan non-solvent (isopropanol) and a solvent (water), provided a tight control over the chitosan membranes swelling capability. The different swelling ratio, obtained at different solvent composition of the reaction mixture, drives simultaneously the monomer solubility and diffusion into the polymeric matrix, the polymerization reaction rate, as well as the eventual chain transfer to the side substituents of the pyranosyl groups of chitosan. A combined analysis of the modified membranes chemistry by proton nuclear magnetic resonance ( $\left.{ }^{1} \mathrm{H}-\mathrm{NMR}\right)$, Fourier transform spectroscopy with attenuated total reflection (FTIR-ATR) and X-ray photoelectron spectroscopy (XPS) showed that it was possible to control the chitosan modification yield and depth in the solvent composition range between $75 \%$ and $100 \%$ of isopropanol. Plasma treatment was also applied to the original chitosan membranes in order to improve cell adhesion and proliferation. Chitosan membranes, which had been previously subjected to oxygen plasma treatment, were then modified by means of the previously described methodology. A human fetal lung fibroblast cell line was cultured until confluence on the
\end{abstract}

Correspondence to: R.M.P. da Silva

Contract grant sponsor: European NoE EXPERTISSUES

Contract grant number: NMP3-CT-2004-500283

Contract grant sponsor: European Union

Contract grant number: NMP3-CT-2003-505758 plasma-treated thermo-responsive chitosan membranes and cell sheets were harvested lowering the temperature.

Biotechnol. Bioeng. 2008;101: 1321-1331.

(C) 2008 Wiley Periodicals, Inc.

KEYWORDS: chitosan; thermo-responsive; isopropylacrylamide; surface modification; cell sheet engineering

\section{Introduction}

Poly( $N$-isopropylacrylamide) (PNIPAAm) is a soluble polymer in cold water that present a sudden precipitation upon heating above the lower critical solution temperature (LCST), at around $32^{\circ} \mathrm{C}$ in pure water (Fujishige et al., 1989; Kubota et al., 1990; Scarpa et al., 1967). This transition involves the breakage of intermolecular hydrogen bonds with the water molecules, which are replaced by intramolecular hydrogen bonds amongst the dehydrated amide groups. Subsequently, the PNIPAAm molecules assume a globule conformation, exposing the hydrophobic isopropyl groups to the water interface (Baysal and Karasz 2003; Graziano 2000). Therefore, when immobilized onto a solid substrate, the LCST behavior of PNIPAAm render the surface with thermo-responsive wettability (da Silva et al., 2007). The temperature control over the wettability of the PNIPAAm-grafted substrates has been used to modulate protein adsorption (Duracher et al., 2004; Huber et al., 2003; Yamato et al., 2000) and confluent cells cultured on such substrates can be recovered as a contiguous cell sheet just by lowering the temperature (da Silva et al., 2007; Kikuchi and Okano, 2005; Shimizu et al., 2003; Yang et al., 2005). In 
conventional cell culture on tissue culture polystyrene (TCPS), cells are harvested disaggregating the extracellular matrix (ECM) through the enzymatic action of trypsin and by simultaneously chelating the $\mathrm{Ca}^{2+}$ and $\mathrm{Mg}^{2+}$ ions with ethylenediaminetetraacetic acid (EDTA). However, nonspecific proteases may damage critical cell surface proteins, such as ion channels and receptors, which constitute a major drawback of this cell harvesting method (Canavan et al., 2005; Ide et al., 2006; Nakajima et al., 2001; Von Recum et al., 1999; Yamada et al., 1990). Besides that, the recovery of the cells, together with the intact newly deposited ECM, represents an increased therapeutic potential with respect to the same single cells harvested by the conventional proteolytic methods, unable to keep cells confluence.

The so-called cell sheet engineering has been mainly performed using TCPS dishes grafted with PNIPAAm (da Silva et al., 2007), which are rigid non-swollen supports. The confluent cell sheets cultured in these thermo-responsive substrates present relatively long-detachment times. Several attempts have been made to accelerate the thermal harvesting process, such as grafting PNIPAAm onto porous supports (Kwon et al., 2000) and co-grafting PNIPAAm with poly(ethylene glycol) (PEG) (Kwon et al., 2003). Another noteworthy approach was based on a multifunctional linear block copolymer, poly $(\mathrm{N}$-isopropylacrylamide-co-acrylic acid)- $b$-poly(L-lactic acid). In this approach small amounts of acrylic acid were used to accelerate the detachment and the poly(L-latic acid) block assured that the copolymer could be easily processed in nonconventional shapes (Kim et al., 2005).

The potential of cell sheet engineering in the regenerative medicine field has been fostered by the development of manipulation techniques which allow transferring the fragile cell sheets from the thermo-responsive culture substrate to the desired place (Harimoto et al., 2002; Shimizu et al., 2001; Yamato et al., 2001). Single cell sheets has been transplanted directly to human patients for cornea regeneration tissues (Nishida et al., 2004), but they can also be layered in order to recreate thicker tissue-like constructs with homotypic (Shimizu et al., 2002) or heterotypic (Harimoto et al., 2002) cells. However, the number of cell sheets that can be effectively layered without core ischemia or hypoxia is limited, because of restrictions on the delivery of nutrients and accumulation of metabolic wastes (Yang et al., 2005). The thermo-responsive surfaces fabricated to harvest intact cell sheets can also be used to keep the multilayered cell sheets in culture for a certain period of time and to allow the thermal recovery of the thicker constructs. It should be noticed that the thermo-responsive PNIPAAm-grafted TCPS substrates commonly used to culture single cell sheets are impermeable, which would decrease the rate of elimination of metabolic wastes and of nutrients supplying, since the construct side facing the culture surface would be wasted as a potential mass transfer area.

In this work, we propose a methodology to grafted PNIPAAm on chitosan membranes aiming at being used as novel substrates for cell sheet engineering and manipulation.
Chitosan is the soluble derivative of chitin obtained by $\mathrm{N}$ deacetylation, which biocompatibility and non-toxicity make it an excellent candidate as a raw material in the biomedical field (Kumar, 2000). Chitosan has been proposed for a range of controlled drug release formulations (Prabaharan and Mano, 2005; Wang et al., 2007), as rate controlling membranes in transdermal delivery systems (Siddaramaiah et al., 2006; Thacharodi and Panduranga Rao, 1996), as a biomaterial (Lopez-Perez et al., 2007; Silva et al., 2004a,b) and for tissue engineering (Baran et al., 2004; Mano and Reis, 2007; Patel et al., 2007; Silva et al., 2007; Tuzlakoglu et al., 2004). We previously developed chitosan membranes that possess adequate permeation properties for the rapid elimination or delivery of small molecules (da Silva et al., accepted). The use of these membranes grafted with PNIPAAm, if able to functioning as substrate for the thermal recovery of confluent cell sheets, would increase the mass transfer area for nutrients and metabolic wastes, hopefully supporting the culture of thicker layered cell sheet constructs. It has been shown that primary human oral mucosa epithelial cells create stratified epithelial layers when cultured on submicron porous thermo-responsive supports, even if cultured without 3T3 feeder layers and fetal bovine serum (Murakami et al., 2006a,b). Murakami el al. proposed that these results might be explained by the exchange of metabolites, which can occur from beneath the basal layer of the cultured epithelium. In this way, the culture conditions mimic more closely the in vivo state.

Moreover, the PNIPAAm-grafted chitosan membranes reported herein will also be useful to transfer the cell sheets directly to the host site with minimal manipulation. Finally, fully hydrated chitosan membranes should be easily adaptable to several anatomical shapes, owning to its mechanical flexibility (Silva et al., 2004b).

\section{Materials and Methods}

\section{Chitosan Material and Other Reagents}

Chitosan raw-material from crab shells were purchased from Sigma-Aldrich (St. Louis, MO) and purified prior to use. Chitosan was dissolved at $\sim 1 \%(\mathrm{w} / \mathrm{v})$ in an aqueous acetic acid solution $(1 \% \mathrm{w} / \mathrm{v})$. The solution was filtered to remove the insoluble material. The clear solution obtained was precipitated adding a $\mathrm{NaOH}$ solution to form a white gel, which was sieved to remove the exuded liquid. This gel was thoroughly washed with distilled water (until no changes on the $\mathrm{pH}$ were detected), further washed/dehydrated with ethanol, freeze-dried, ground to powder and dried at $60^{\circ} \mathrm{C}$ overnight. $\quad N$-Isopropylacrylamide (NIPAAm) (Acros-Organic, Morris Plains, NJ) was recrystallized from a $n$-hexane/diethyl ether (5:1) mixture and dried overnight to remove residual solvent. All other reagents were used without further purification.

The chitosan average molecular weight was of found to be $660 \mathrm{kDa}$ by viscometry in $\mathrm{CH}_{3} \mathrm{COOH} 0.5 \mathrm{M} / \mathrm{NaCH}_{3} \mathrm{COO}$ 
$0.2 \mathrm{M}$, according to the Mark-Houwing theory $(k=3.5 \times$ $10^{-4} ; a=0.76$ ) (Terbojevich et al., 1996). The degree of $N$-deacetylation (DD) was found to be $65.4 \%$ by means of first derivative UV spectrophotometry, using both glucosamine (GluN) and $N$-acetylglucosamine (GluNAc) standards for calibration (da Silva et al., 2008).

\section{Preparation of Chitosan Membranes by Solvent Casting}

The chitosan solution was prepared by dissolving chitosan (1 wt.\%) in acetic acid solution (1 wt.\%). The solutions were carefully stirred in order to avoid the formation of any air bubble, poured on Petri dishes ( $5 \mathrm{mg}$ of chitosan $/ \mathrm{cm}^{2}$ ) and dried at room temperature in a dust free environment. The resultant membranes (thickness approximately $50 \mu \mathrm{m}$ ) were neutralized in $\mathrm{NaOH} 0.1 \mathrm{M}$ solution for $10 \mathrm{~min}$ and washed thoroughly with distilled water. The obtained membranes (CTS) were hold in a frame and dried again, presenting a smooth surface without the typical wrinkles derived from the material shrinking during the drying process.

\section{Swelling of Chitosan Membranes in Mixtures of Isopropanol and Water}

The swelling of chitosan membranes in mixtures of a nonsolvent (isopropanol) and a solvent (water) was determined by immersing previously weighted chitosan membranes in mixtures of these solvents at compositions varying from pure water to pure isopropanol. After around $2 \mathrm{~h}$, equilibrated samples were blotted with filter paper to remove the adsorbed solvent and weighted immediately. The equilibrium swelling ratio $\left(S_{\text {eq }}\right)$ was calculated using the following equation:

$$
S_{\text {eq }}(\%)=\frac{W-W_{0}}{W_{0}} \times 100
$$

where $W_{0}$ is the initial weight of the sample and $W$ is the weight of the swelled sample.

\section{Surface Modification by Plasma Treatment}

In one of our previous works (Lopez-Perez et al., 2007), plasma treatment of chitosan membranes was very effective on improving the viability and proliferation of osteoblastlike cells. In this sense, the surface of some chitosan membranes was modified by plasma treatment according to that procedure (Lopez-Perez et al., 2007), before PNIPAAm grafting. Briefly, the plasma treatment was performed using a radio frequency $(13.56 \mathrm{MHz})$ Plasma Prep5 equipment from Gala Instrument. Samples were exposed to $\mathrm{O}_{2}$ plasma at $30 \mathrm{~W}$ of power during $15 \mathrm{~min}$. The pressure in the reactor was maintained under $20 \mathrm{~Pa}$ by regulating the gas flow. The samples were only further processed after $48 \mathrm{~h}$ in order to assure that free radicals formed during the plasma treatment have been quenched.

\section{PNIPAAm Grafting Onto and Into Chitosan Membranes}

The monomer (NIPAAm) was dissolved in several compositions of these isopropanol/water mixtures varying in the volume ratio from $(50: 50)$ to pure isopropanol (100:0). The initiator, 2,2'-azobis-isobutyronitrile (AIBN), was dissolved in each solvent mixture used in the respective monomer solution. Chitosan membranes were immersed in the monomer solutions. Both monomer and initiator solutions were deoxygenated under slow nitrogen flow for $10 \mathrm{~min}$. The polymerization was initiated adding the AIBN solution to the monomer solutions and the reaction was performed at $60^{\circ} \mathrm{C}$ under $\mathrm{N}_{2}$ atmosphere for $18 \mathrm{~h}$. The volumes of NIPAAM and AIBN solutions give a final monomer concentration of $0.25 \mathrm{~g} / \mathrm{mL}$ and AIBN to NIPAAm molar ratio of $1 \%$. The grafted membranes were washed thoroughly with water/acetone (25:75) to remove un-reacted monomer and unbound polymer. Samples were labeled as iPrOH100, iPrOH90, iPrOH75 and iPrOH50, according to the volume of isopropanol used in the non-solvent/solvent mixture composition. The same PNIPAAm grafting procedure was also applied to plasma-treated chitosan membranes at an isopropanol/water composition of 75:25 (P-iPrOH75).

\section{Assessment of Chitosan Membranes Chemical Modification}

PNIPAAm-grafted membranes were analyzed by Fourier Transform Infrared spectroscopy with the attenuated total reflection (FTIR-ATR) to assess the existence of major chemical changes occurring at lower depth. Spectra were recorded in a Perkin-Elmer (Waltham, USA) Spectrum One spectrophotometer (32 scans, resolution $4 \mathrm{~cm}^{-1}$ ). Proton nuclear magnetic resonance $\left({ }^{1} \mathrm{H}-\mathrm{NMR}\right)$ was used to estimate the total amount of grafted PNIPAAm, which were thought to be detectable for samples in which grafting reaction was performed in solvents with higher water content. Around $10 \mathrm{mg}$ of each membrane sample was dissolved in $1 \mathrm{~mL}$ of $0.4 \%(\mathrm{w} / \mathrm{v})$ of deuterium chloride $(\mathrm{DCl})$ in $\mathrm{D}_{2} \mathrm{O}$ solution at room temperature. PNIPAAm spectrum was obtained dissolving in $\mathrm{D}_{2} \mathrm{O}$. The ${ }^{1} \mathrm{H}-\mathrm{NMR}$ spectra were acquired in a VARIAN INOVA-300 (300 MHz) spectrometer.

\section{X-Ray Photoelectron Spectroscopy (XPS)}

Possible chemical changes occurred on the surfaces after the modification were evaluated by XPS. The spectra were obtained using an ESCALAB 200A instrument from VG Scientific (UK) with PISCES software for data acquisition and analysis. A monochromatic $\mathrm{Al} \mathrm{K} \alpha$ radiation $(h v=$ $1486.60 \mathrm{eV})$ operating at $15 \mathrm{kV}(300 \mathrm{~W})$ was used. The measurements were performed in a constant analyzer energy mode (CAE) and take off angle of $90^{\circ}$ relative to the sample 
surfaces. Survey spectra were acquire using a pass energy of $50 \mathrm{eV}$, over a binding energy range of $0-1,100 \mathrm{eV}$, and were used to calculate the elemental composition of the surfaces. Element atomic percentages were calculated from the integrated intensities of the survey spectra using the sensitivity factor of the instrument data system. Highresolution spectra for different regions $(\mathrm{C} 1 \mathrm{~s}, \mathrm{O} 1 \mathrm{~s}$ and $\mathrm{N} 1 \mathrm{~s})$ were obtained using a pass energy of $20 \mathrm{eV}$ and were peakfitted using a least-squares peak analysis software, XPSPEAK version 4.1, using the Gaussian/Lorenzian sum function. Background counts were subtracted using a linear baseline and the sample charging was corrected assigning a binding energy of $285.0 \mathrm{eV}$ to the saturated hydrocarbons $\mathrm{C} 1 \mathrm{~s}$ peak.

\section{Water Uptake Kinetics and Equilibrium Hydration Degree}

The water uptake measurements were undertaken in phosphate buffer saline (PBS) solution, prepared dissolving PBS tablets (Sigma Chemical Co., St. Louis, MO) in a suitable amount of water $(\mathrm{NaCl} 0.137 \mathrm{M}$; $\mathrm{KCl} 0.0022 \mathrm{M}$; phosphate buffer $0.01 \mathrm{M} ; \mathrm{pH} 7.4$ at $25^{\circ} \mathrm{C}$ ). The water uptake was determined immersing previously weighted chitosan membranes in buffer solution at $37 \pm 1^{\circ} \mathrm{C}$. After each time period samples were blotted with filter paper to remove the adsorbed water and weighted immediately. The calculation of the water uptake (WU) was also based on equation (1). The equilibrium hydration degree $\left(\mathrm{WU}_{\mathrm{eq}}\right)$ in $\mathrm{PBS}$ solution was taken as the last point of the water sorption kinetic curves.

\section{Cell Culture}

A human fetal lung cell line (MRC-5), an immortalized cell line with fibroblast-like morphology, was obtained from European Collection of Cell Cultures (ECACC, UK) and was used in the cell culture studies. The cells were cultured in Dulbecco's Modified Eagle's Medium (DMEM; SigmaAldrich, Inc.) supplemented with $10,000 \mathrm{U} / \mathrm{mL}$ penicillin-G sodium, 10,000 $\mu \mathrm{g} / \mathrm{mL}$ streptomycin sulfate and $25 \mu \mathrm{g} / \mathrm{mL}$ amphotericin B in a $0.85 \%$ saline (Gibco, Invitrogen Corporation, Paisley, UK) and $10 \%$ of heat-inactivated fetal bovine serum (FBS; Biochrom AG, Berlin, Germany) in a humidified atmosphere with $5 \%$ of $\mathrm{CO}_{2}$ at $37^{\circ} \mathrm{C}$. Membranes were cut with $14 \mathrm{~mm}$ diameter and placed onto 24-well culture plates. Prior to culturing, all samples were sterilized by adding $1 \mathrm{~mL}$ of $70 \%$ ethanol aqueous solution for $90 \mathrm{~min}$ and subsequently washed with sterile phosphate buffered saline solution (PBS, Sigma Chemical Co.) to remove the remaining ethanol. Cells were seeded on the materials at a concentration of $7 \times 10^{4}$ cells $/ \mathrm{mL}, 1 \mathrm{~mL}$ per well and incubated for 10 days, time at which the cells seeded on plasma-treated materials (P-iPrOH75) were $100 \%$ confluent.

\section{Cell Sheet Detachment and Assessment of the Cell Viability}

After 10 days of culture, plates were removed from the incubator and observed by light microscopy. The cells cultured on the different samples were continuously observed to assess the eventual detachment from the surface at room temperature $\left(\mathrm{ca} .16^{\circ} \mathrm{C}\right)$. Cell viability was assessed after Calcein AM staining. A 2:1,000 Calcein AM solution was prepared with DMEM culture medium and 1,000 $\mu \mathrm{L}$ were added to each sample culture. Plates were incubated for $15 \mathrm{~min}$ at $37^{\circ} \mathrm{C}$ in a humidified atmosphere of $5 \% \mathrm{CO}_{2}$ and cell fluorescence examined in an Axioplan Imager Z1 from Zeiss (Göttingen, Germany).

\section{Results and Discussion}

\section{Isopropanol-Water Mixtures Solvent Uptake}

The control of the swelling capability of the chitosan membranes can be tightly achieved by changing the composition of isopropanol and water mixtures. As it can be observed in Figure 1, the swelling equilibrium degree varies linearly with the volume composition of the solvent mixtures for concentrations of isopropanol higher than $10 \%$. The swelling decreases steadily with increasing proportions of isopropanol. On the other hand, the membranes did not swell at all for the pure non-solvent. This result should allow engineering membrane surfaces with different grafting yields and depths, by changing simultaneously the monomer uptake by the membranes (solubility), diffusion into the polymer matrix and the monomer reaction rate on the surface or inside the swollen membranes. Of course, the solvent composition is restricted to the isopropanol volume ratio (higher than $50 \%$ ) in which monomer and initiator are soluble at the polymerization temperature $\left(60^{\circ} \mathrm{C}\right)$.

\section{Assessment of Chitosan Membranes Chemical Modification}

The FTIR spectrum of PNIPAAm presents two intense bands at 1,650 and $1,544 \mathrm{~cm}^{-1}$ (Fig. 2a), which are related to

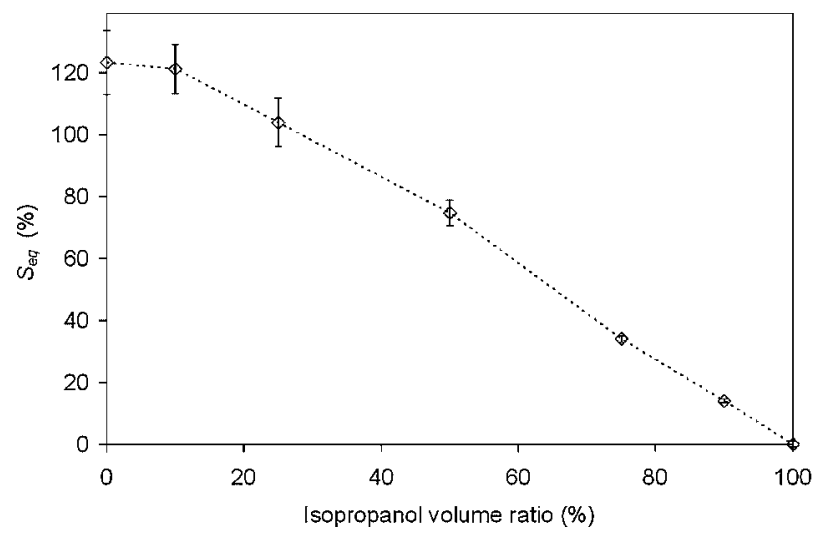

Figure 1. The equilibrium swelling ratio $\left(S_{\text {eq }}\right)$ of chitosan membranes in mixtures of isopropanol and water at varying compositions represented in function of the isopropanol volume ratio. 

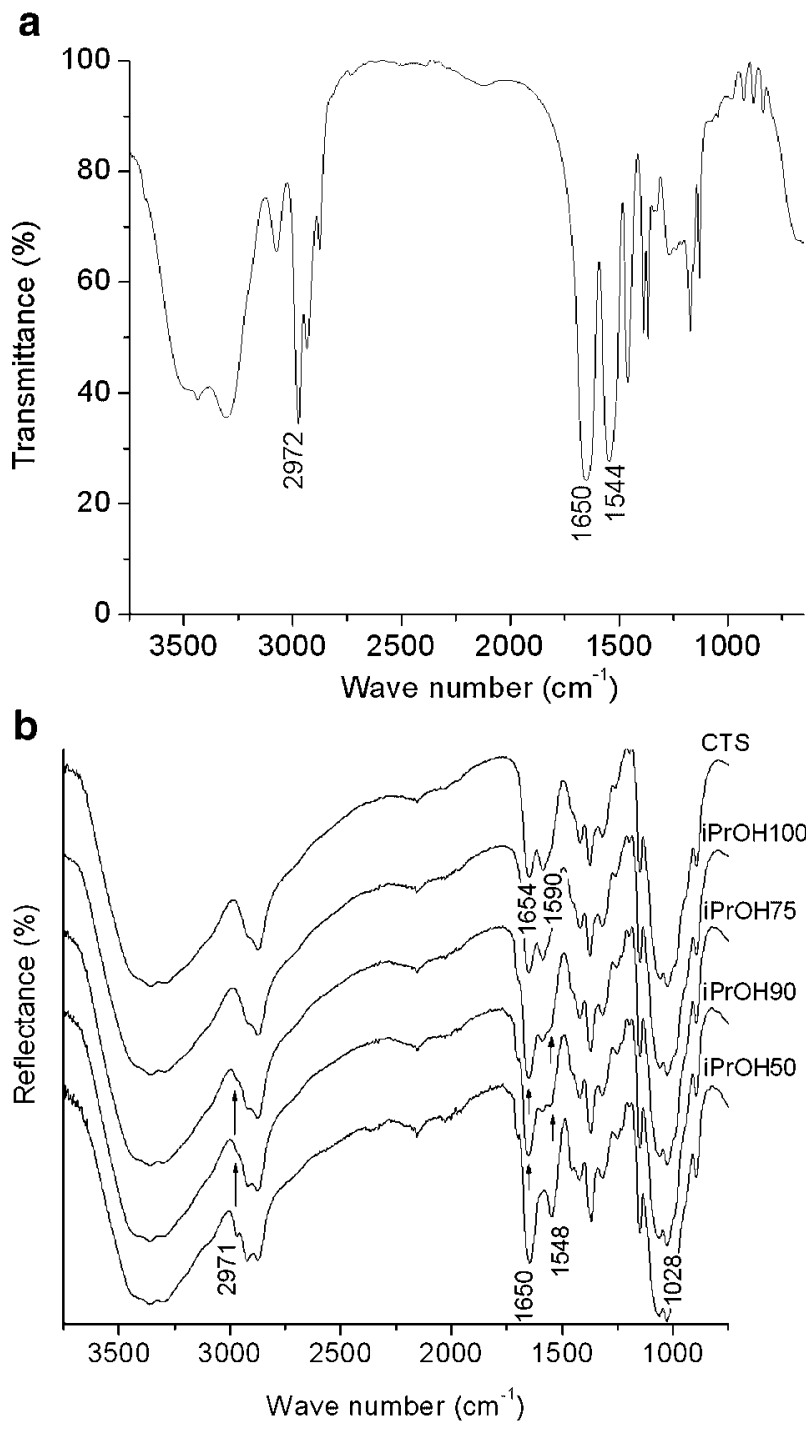

Figure 2. (a) FTIR-ATR spectrum of PNIPAAm; (b) comparative spectra of nongrafted chitosan membranes (CTS) and grafted in mixtures of isopropanol and water at varying compositions (iPrOH100, iPrOH90, $\mathrm{PPrOH} 75$ and $\mathrm{PPrOH} 50)$.

the amide groups. The first is assigned to the stretching vibration of $\mathrm{C}=\mathrm{O}$ group (amide $\mathrm{I}$ ), whereas the second corresponds to the bending vibration of $\mathrm{NH}$ and the symmetric stretching of $\mathrm{N}-\mathrm{C}=\mathrm{O}$ (amide II). The three bands appearing at $2,972,2,932$, and $2,874 \mathrm{~cm}^{-1}$ can be assigned to the stretching vibration of the $\mathrm{C}-\mathrm{H}$ bonds from the isopropyl groups and polymer backbone. The band at $2,972 \mathrm{~cm}^{-1}$ is particularly intense.

In the chitosan membranes (CTS) spectrum (Fig. 2b), amide II band is observed at $1,590 \mathrm{~cm}^{-1}$. The intensity of the band at $1,645 \mathrm{~cm}^{-1}$, which is assigned to stretching vibration of carbonyl group (amide I), is in good agreement with the low deacetylation degree of the used chitosan. The bands assigned to the stretching vibration of $\mathrm{C}-\mathrm{O}-\mathrm{C}$ linkages in the polysaccharide structure appear at $1,151,1,060,1,027$, and $895 \mathrm{~cm}^{-1}$. The weak bands at 2,927 and $2,874 \mathrm{~cm}^{-1}$ correspond to the stretching vibration of the $\mathrm{C}-\mathrm{H}$ bonds.

The non-swollen membranes modified in pure isopropanol exhibit an infrared spectrum very similar to the nonmodified membranes (CTS) (Fig. 2b). Nevertheless, it does not mean that the surface has not been modified, because in the FTIR-ATR technique the penetration depth of the IR radiation beam is around $1-5 \mu \mathrm{m}$ into the polymer membrane at each internal reflection (Ratner, 1996). Therefore, information cannot be inferred if the modification only affects the topmost layers of the sample, as it would be expected for the non-swollen membranes.

In the membrane samples modified in an isopropanol content higher than $90 \%$ a shoulder or band appears at the amide II region between 1,590 and $1,548 \mathrm{~cm}^{-1}$ (see Fig. 2b), which becomes more intense as the solvent swelling ratio increases (from $100 \%$ to $50 \%$ of isopropanol), indicating a gradual increase in the amount of PNIPAAm. In fact, in the spectrum of iPrOH50 the amide II band suffered a displacement to $1,548 \mathrm{~cm}^{-1}$, which is consistent with the wave number of that band in PNIPAAm. It is also observed an increase on the intensities of the amide I band that can be explained due to the cumulative contribution of PNIPAAm amide groups $(\mathrm{C}=\mathrm{O})$ and of the chitosan acetyl groups $(\mathrm{C}=$ $\mathrm{O})$. Furthermore, the relative intensity of the characteristic chitosan $\mathrm{C}-\mathrm{H}$ stretching bands at 2,874 and $2,927 \mathrm{~cm}^{-1}$ changed gradually and a new band appears at $2,972 \mathrm{~cm}^{-1}$ (iPrOH50), which corresponds to the particularly intense $\mathrm{C}-\mathrm{H}$ stretching band in the PNIPAAm spectrum. The described spectral changes point out an increase in the amount of PNIPAAm in a superficial region of the membranes $(1-5 \mu \mathrm{m})$ when going from $\mathrm{iPrOH} 90$ to iPrOH50, i.e., when increasing the polymerization solvent swelling ratio.

The ${ }^{1} \mathrm{H}$-NMR spectroscopy results (Fig. 3 ) give quantitative information with respect to the bulk modification yield. PNIPAAm pure homopolymer (see Fig. 4) was previously dissolved in $\mathrm{D}_{2} \mathrm{O}$ and the proton chemical shifts $(\delta)$ were assigned: $\delta 1.00\left(-\mathrm{CH}_{3}\right.$, isopropyl group), 1.42 ( $-\mathrm{CH}_{2}-$, polymer chain), 1.78 (-CH-, polymer chain), and 3.76 (-CH-, isopropyl group). Only the first two peaks are well resolved from the chitosan spectrum. On the other hand, the chitosan peak assigned to the $\mathrm{H} 2$ proton $(\delta 2.95)$ of the GluN units is the only peak well resolved both from the PNIPAAm spectrum and from the HOD signal.

We used the PNIPAAm peak from the isopropyl $-\mathrm{CH}_{3}$ groups (six protons) to estimate the amount of this polymer relative to the amount of chitosan, which in turn was estimated using the GluN $\mathrm{H} 2$ proton signal and the DD value. It is clear from Figure 3 that PNIPAAm is undetectable for the samples treated under solvent conditions less favorable for swelling (iPrOH90 and iPrOH100). This means that the modification for low and non-swelling conditions, respectively, is much more superficial, as it would be expected. In turn, the relative amount of PNIPAAm is considerable high for iPrOH75 (5.3 wt.\%) 


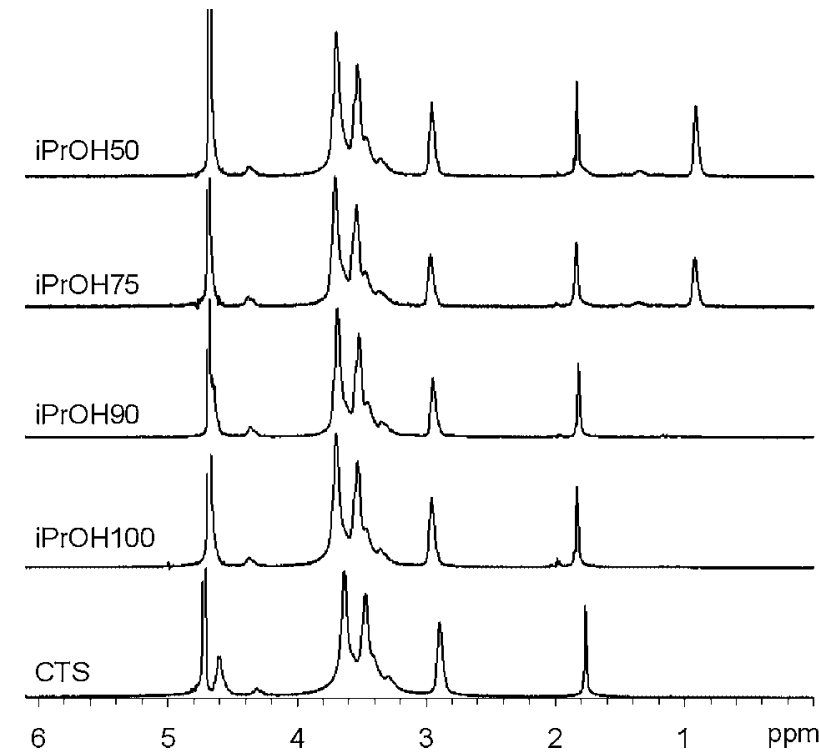

Figure 3. ${ }^{1} \mathrm{H}-\mathrm{NMR}$ spectra of non-grafted chitosan membranes (CTS) and grafted in mixtures of isopropanol and water at varying compositions (iPrOH100, iPrOH90, iPrOH75 and iPrOH50).

and only increases a little for iPrOH50 (5.5 wt.\%), indicating a much higher modification depth of these membranes.

\section{Surface Analysis by X-Ray Photoelectron Spectroscopy (XPS)}

The surface chemical composition of modified (iPrOH75 and $\mathrm{PPOH} 100)$ and non-modified membranes (CTS) was evaluated by XPS analysis. Table I shows the elemental composition of the surfaces (at.\%) extracted from the survey spectra. Carbon, oxygen and nitrogen appeared as major components for all the samples, as it was expected considering the chemical structure of chitosan and PNIPAAm (Fig. 4). Some impurities (Ca, $\mathrm{Cl}$, and $\mathrm{Zn}$ ) were also found, in very low percentage $(<0.5 \%)$ in the composition of some of the samples and were not considered for the element analysis. After the grafting, a polymer chain $\left(-\mathrm{CH}_{2}-\mathrm{CH}-\right)$ is introduced on the membranes surface and as it was expected, the $\mathrm{C} 1 \mathrm{~s}$ percentage increased in the modified samples compared with the untreated one.
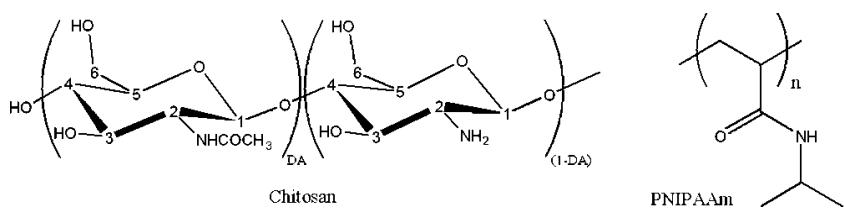

Figure 4. Chemical structures of chitosan and PNIPAAm.
Table I. Elemental composition (at.\%) of untreated chitosan membranes (CTS) and modified materials (iPrOH75 and iPrOH100) calculated from the XPS survey spectra.

\begin{tabular}{lrcc}
\hline Element & CTS & iPrOH75 & iPrOH100 \\
\hline C 1s (at.\%) & 65.1 & 77.5 & 74.3 \\
O 1s (at.\%) & 29.2 & 21.0 & 22.5 \\
N 1s (at.\%) & 5.7 & 1.5 & 3.2 \\
\hline
\end{tabular}

Figure 5a shows the binding energy region corresponding to C 1s peak (279.8-191.9 eV) for CTS samples. The peakfitting was performed according with the chitosan chemical structure. The peak at $285.0 \mathrm{eV}$ was assigned to $\mathrm{C}-\mathrm{H}$ and $\mathrm{C}-$ $\mathrm{C}$ chemical bonds of the chitosan backbone. The second peak at $286.4 \mathrm{eV}$ corresponded to $\mathrm{C}-\mathrm{OH}, \mathrm{C}-\mathrm{O}$ and $\mathrm{C}-\mathrm{N}-\mathrm{C}=$ $\mathrm{O}$ carbons and, finally, the peak centered at $287.6 \mathrm{eV}$ was assigned to $\mathrm{O}-\mathrm{C}-\mathrm{O}$ and $\mathrm{N}-\mathrm{C}=\mathrm{O}$ from the acetylated rings. It was not possible to perform the deconvolution of the band corresponding to $\mathrm{C}-\mathrm{NH}_{2}$ bond, because amines are reported to induce small chemical shifts (around $0.6 \mathrm{eV}$ ) (Briggs, 1998) and the band should be superimposed by the band of the hydrocarbons chemical bonds in chitosan, observed at $285.0 \mathrm{eV}$.

In the case of linear PNIPAAm, it is expected a C 1s spectra containing four peaks, allocated in the same position that chitosan peaks. Peaks at $285.0 \mathrm{eV}$ and around $285.4 \mathrm{eV}$ should be associated to hydrocarbons in the polymeric
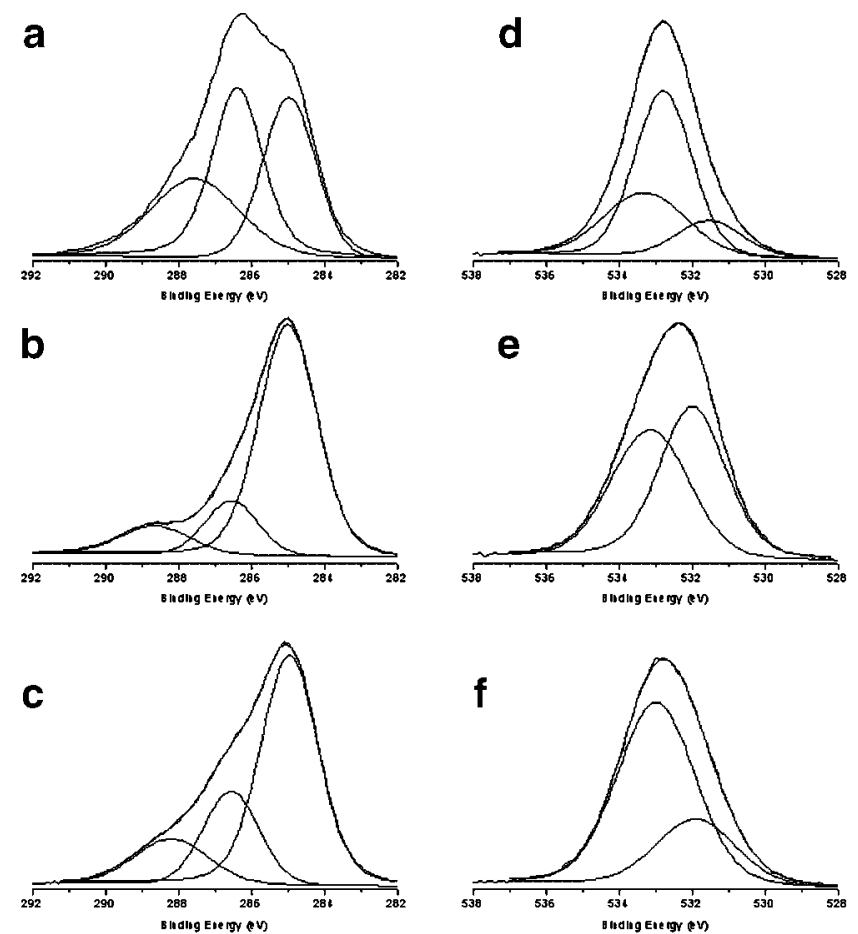

Figure 5. XPS high-resolution spectra for $\mathrm{C} 1 \mathrm{~s}$ (left) and 0 1s (right). From top to down: CTS, iPrOH75 and iPrOH100. 
Table II. C 1s and O 1s core levels composition (\%) for CTS, iPrOH75 and iPrOH100.

\begin{tabular}{|c|c|c|c|c|c|c|c|}
\hline \multicolumn{4}{|l|}{ C 1s core level } & \multicolumn{4}{|c|}{ O 1s core level } \\
\hline Bond & CTS & iPrOH75 & iPrOH100 & Bond & CTS & iPrOH75 & iPrOH100 \\
\hline$\underline{\mathrm{C}}-\mathrm{C} ; \underline{\mathrm{C}}-\mathrm{H}$ & 33.0 & 75.3 & 63.4 & $\mathrm{~N}-\mathrm{C}=\underline{\mathrm{O}}$ & 14.0 & 52.8 & 27.0 \\
\hline$\underline{\overline{\mathrm{C}}}-\mathrm{O} ; \underline{\overline{\mathrm{C}}}-\mathrm{N}-\mathrm{C}=\mathrm{O}$ & 38.8 & 14.8 & 22.4 & $\mathrm{C}-\underline{-} \mathrm{H}$ & 56.6 & 47.2 & 73.1 \\
\hline$\overline{\mathrm{N}}-\mathrm{C}=\overline{\mathrm{O}} ; \mathrm{O}-\underline{\mathrm{C}}-\mathrm{O}$ & 28.3 & 9.9 & 14.1 & $\underline{\mathrm{O}}-\overline{\mathrm{C}}-\underline{\mathrm{O}}$ & 29.4 & 0.0 & 0.0 \\
\hline
\end{tabular}

backbone. The peak corresponding to $\mathrm{C}-\mathrm{N}-\mathrm{C}=\mathrm{O}$ should be situated around $286.5 \mathrm{eV}$ and the carbon from the carbonyl group $(\mathrm{N}-\mathrm{C}=\mathrm{O})$ should be allocated around $288.0 \mathrm{eV}$ (Adem et al., 2005; Bullett et al., 2006).

Figure $5 \mathrm{~b}$ and $\mathrm{c}$ shows the $\mathrm{C} 1 \mathrm{~s}$ region for the samples iPrOH75 and iPrOH100, respectively. The intensity of the band corresponding to the hydrocarbon bonds increases in both cases compared with CTS (Table II), providing evidence that PNIPAAm polymer chains have been introduced on the surface through the modification procedure. In the case of the sample iPrOH100, this result had not been possible to confirm using less surface sensitive techniques such as FTIR-ATR, showing that the PNIPAAm chains grafting occurred at a very superficial level (the FTIRATR penetration depth of the FTIR-ATR analysis is in the range of $1-5 \mu \mathrm{m}$ (Ratner, 1996)).

The binding energy region corresponding to $\mathrm{O} 1 \mathrm{~s}$ peak $(394.0-404.0 \mathrm{eV})$ for chitosan is showed in Figure 5d. The peak at $531.5 \mathrm{eV}$ was assigned to carbonyl oxygen $(\mathrm{N}-\mathrm{C}=\mathrm{O})$ presented in the $\mathrm{N}$-acetyl-glucosamine rings. Oxygen atoms involved in hydroxyl bonds $(\mathrm{C}-\mathrm{OH})$ were included in the peak appearing at $532.8 \mathrm{eV}$. The peak at $533.3 \mathrm{eV}$ was identified as characteristic of the $\mathrm{O}-\mathrm{C}-\mathrm{O}$ bonds.

PNIPAAm only posses one oxygen atom per polymer molecule been involved in amide bonds $(\mathrm{N}-\mathrm{C}=\mathrm{O})$. Therefore, after the grafting, it was expected an increase in the peak allocated around $531.5 \mathrm{eV}$ relatively to the peaks contained single $\mathrm{C}-\mathrm{O}$ bonds. As can be observed from values showed in Table II, when the modification is performed using isopropanol at $75 \%$ (Fig. 5e) the first peak became much more intense, corroborating the PNIPAAm grafting. On the other hand, when $100 \%$ isopropanol was used for the grafting reaction (Fig. 5f), this increase was not so drastic showing that the grafting occurred but at lower extent.

\section{Chitosan Membranes Equilibrium Hydration Degree}

The chitosan membranes water uptake kinetics (Fig. 6) in PBS solution was very fast, the equilibrium hydration degree $\left(\mathrm{WU}_{\mathrm{eq}}\right)$ being achieved in less than $5 \mathrm{~min}$. It is interesting to notice that the non-modified chitosan membranes (CTS) presented the higher $\mathrm{WU}_{\mathrm{eq}}$ of approximately $160 \%$ and that it decreases from iPrOH100 to iPrOH75, being lower for membranes polymerized at higher swelling solvent conditions. During the NIPAAm polymerization the growing polymer chains predictably occupy the spaces created by the swelling in the reaction solvent. Being so, the conditions that induce higher swelling rates should allow for the entrance of higher amounts of newly formed polymer. Interestingly, the $\mathrm{WU}_{\mathrm{eq}}$ is inversely related to the amount of PNIPAAm chains that entered the chitosan membranes pre-established molecular network.

On the other hand, the iPrOH50 equilibrium hydration degree was higher than that of iPrOH75, oppositely to what would be expected. Nevertheless, although the monomer and initiator are both soluble at the polymerization conditions of isopropanol at $50 \%$ and $60^{\circ} \mathrm{C}$, the polymerized NIPAAm precipitates partially, which may explain such discontinuity in the tendency of equilibrium hydration degree. The precipitation of the newly formed PNIPAAm also explains why the bulk grafting yield calculated by ${ }^{1} \mathrm{H}$ NMR is quite similar for both iPrOH50 and iPrOH75 samples, although the swelling of the chitosan membranes in isopropanol at $50 \%$ is twice than that determined at $75 \%$.

\section{PNIPAAm Covalent Grafting Versus Chain Entanglement}

The immobilization of PNIPAAm chains on the membranes may take place by means of covalent bonds, formed by transfer reactions of the growing PNIPAAm radicals to the side substituents of the pyranosyl groups of chitosan. In radical polymerization, the growth of each radical proceeds by successive addiction of monomer units until interrupted

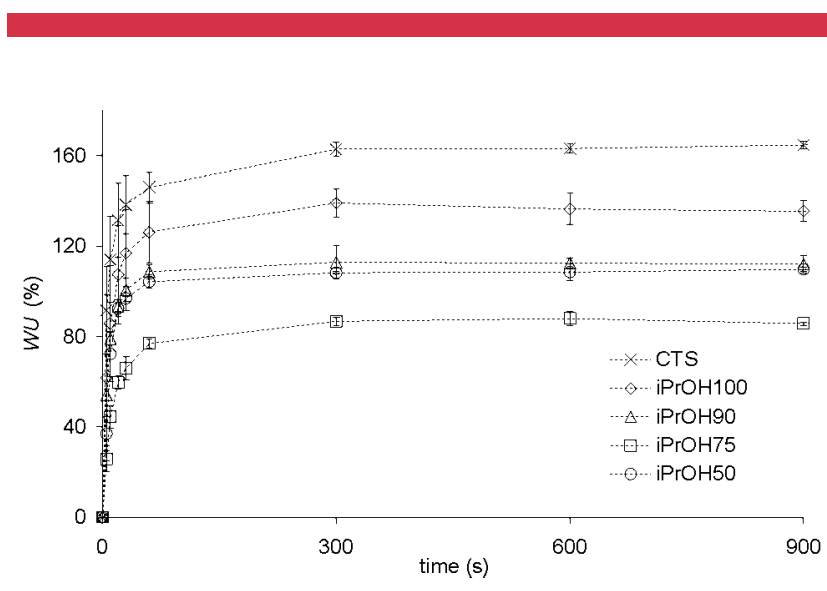

Figure 6. Water uptake kinetics in $\mathrm{PBS}$ solution $\left(37^{\circ} \mathrm{C}\right)$ of non-grafted chitosan membranes (CTS) and grafted in mixtures of isopropanol and water at varying compositions ( $\mathrm{PPrOH} 100$, iPrOH90, iPrOH75 and $\mathrm{PrOH} 50$ ). Data represents mean \pm standard deviation for $n=3$. 
by one of the chain termination mechanisms, such as for instance chain transfer. Chain transfer reactions may occur towards the solvents, initiator, monomers, impurities or other molecules present in the reaction system, in an extent that depends on the chain transfer constant of each individual component, according to the Mayo equation (Mayo, 1943). It has been reported that grafting of poly(vinyl acetate) to poly(vinyl alcohol) occurs through a chain transfer mechanism (Okaya et al., 2004). Moreover, it was found that poly(acrylic acid-co-acrylamide) chains may be grafted onto starch-based polysaccharides by transfer reactions of the growing radicals on the side substituents of the pyranosyl cycles (Elvira et al., 2002). In fact, chain transfer seems to be an important mechanism on the grafting of PNIPAAm onto chitosan membranes. The XPS core level spectra for $\mathrm{C} 1 \mathrm{~s}$ and $\mathrm{O} 1 \mathrm{~s}$ show that PNIPAAm is grafted on the surface of non-swollen chitosan membranes (iPrOH100), in which chain entanglement is not an expected mechanism for PNIPAAm chains immobilization. In fact, the non-swollen nature of these samples (iPrOH100) should not allow the penetration of the growing radical and the samples were thoroughly washed with water/ acetone to remove the non-grafted PNIPAAm. In the other samples (iPrOH50, iPrOH75, P-iPrOH75 and iPrOH90), polymer chains physical entanglement cannot be discharged as a possible mechanism for PNIPAAm immobilization. Nevertheless, according to the Mayo theory (Mayo, 1943), grafting through chain transfer reaction should be favored inside the membrane, because chitosan (chain transfer agent) concentration is much higher in the interior of the swollen members than at the surface level, oppositely to the solvent concentration, which is higher at the membranes surface.

\section{Cell Sheet Detachment and Assessment of the Cell Viability}

The non-modified chitosan membranes (CTS) showed poor cell adhesion and proliferation (see Fig. 7). The few viable cells adhered on the CTS sample surface after 10 days of culture did not present the typical fibroblast-like morphology, being quite round and sparsely distributed. The poor cell adhesion and proliferation on chitosan membranes have been previously reported (Lopez-Perez et al., 2007; Zhu et al., 2005). The iPrOH50 membranes presented very similar results (not shown). In turn, the cells cultured on the membranes modified using solvent compositions varying from $75 \%$ to $100 \%$ of isopropanol presented the typical elongated fibroblastic morphology. Moreover, it was possible to observe regions on the surface of these samples where cells reach the confluence, but also regions with only few adhered cells. Although the modification with PNIPAAm improved the surface properties in terms of cell behavior, they did not present adequate cell proliferation to reach confluence all over the samples surface, within the predetermined culture period. As our aim is to be able to create
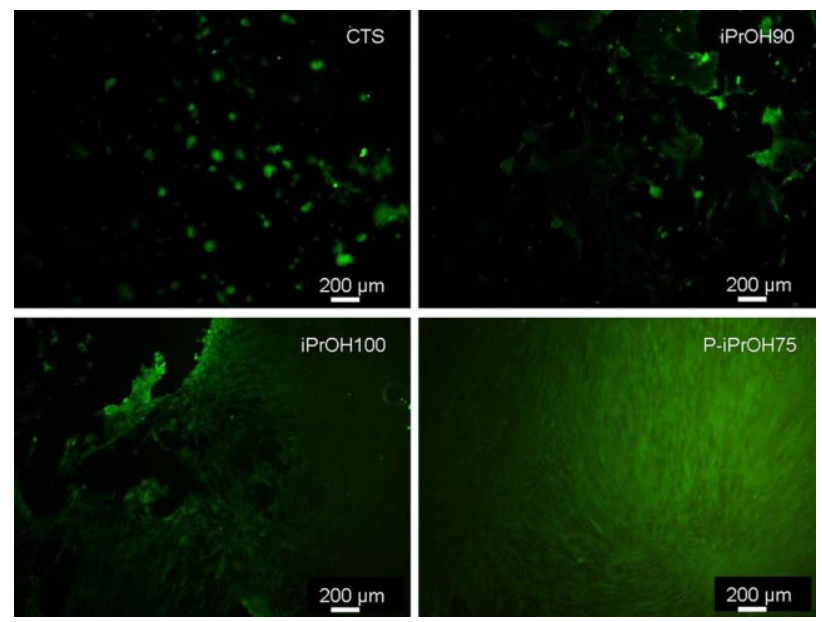

Figure 7. Fluorescence microscopy of viable human fetal lung fibroblast cells stained with calcein AM solution in DMEM culture medium and after 10 days of culture on both non-modified chitosan membranes (CTS) and PNIPAAm grafted (iPrOH90, PiPrOH75 and $\mathrm{PrOH} 100)$. [Color figure can be seen in the online version of this article, available at www.interscience.wiley.com.]

cell sheets, which can be harvested by simply lowering the temperature, cell confluence is a critical parameter to achieve. In one of our previous works (Lopez-Perez et al., 2007), plasma treatment was very effective on improving the viability and proliferation of osteoblast-like cells. It is wellknown that the surface energy has a striking effect on the cell behavior. We were able to modify chitosan membranes surface by using a suitable oxygen plasma treatment, improving the cell viability and proliferation, which was correlated with both moderate polar and Lewis base components for the surface energy.

In this sense, in this work we used the same PNIPAAm grafting procedure on plasma-treated chitosan membranes (P-iPrOH75). Fully confluent and viable cell sheets were formed on this sample after 10 days of culture (see Fig. 7). As it can be observed in Figure 8, the confluent cell sheets were harvested from the modified thermo-responsive chitosan membranes ( $\mathrm{P}$-iPrOH75) keeping the cultured cells at room temperature (ca. $16^{\circ} \mathrm{C}$ ). Although it was not possible to reach $100 \%$ confluence on the other PNIPAAm modified chitosan membranes (iPrOH50, iPrOH75, iPrOH90 and iPrOH100), we were able to observe the low temperature detachment of some single cells and smaller patches of confluent cells.

\section{Conclusions}

The control of the swelling capability of the chitosan membranes could be tightly achieved by changing the composition of isopropanol and water mixtures, providing a suitable mean to tailor the modification yield and depth. The changes in the FTIR-ATR spectra point out to an increase in 

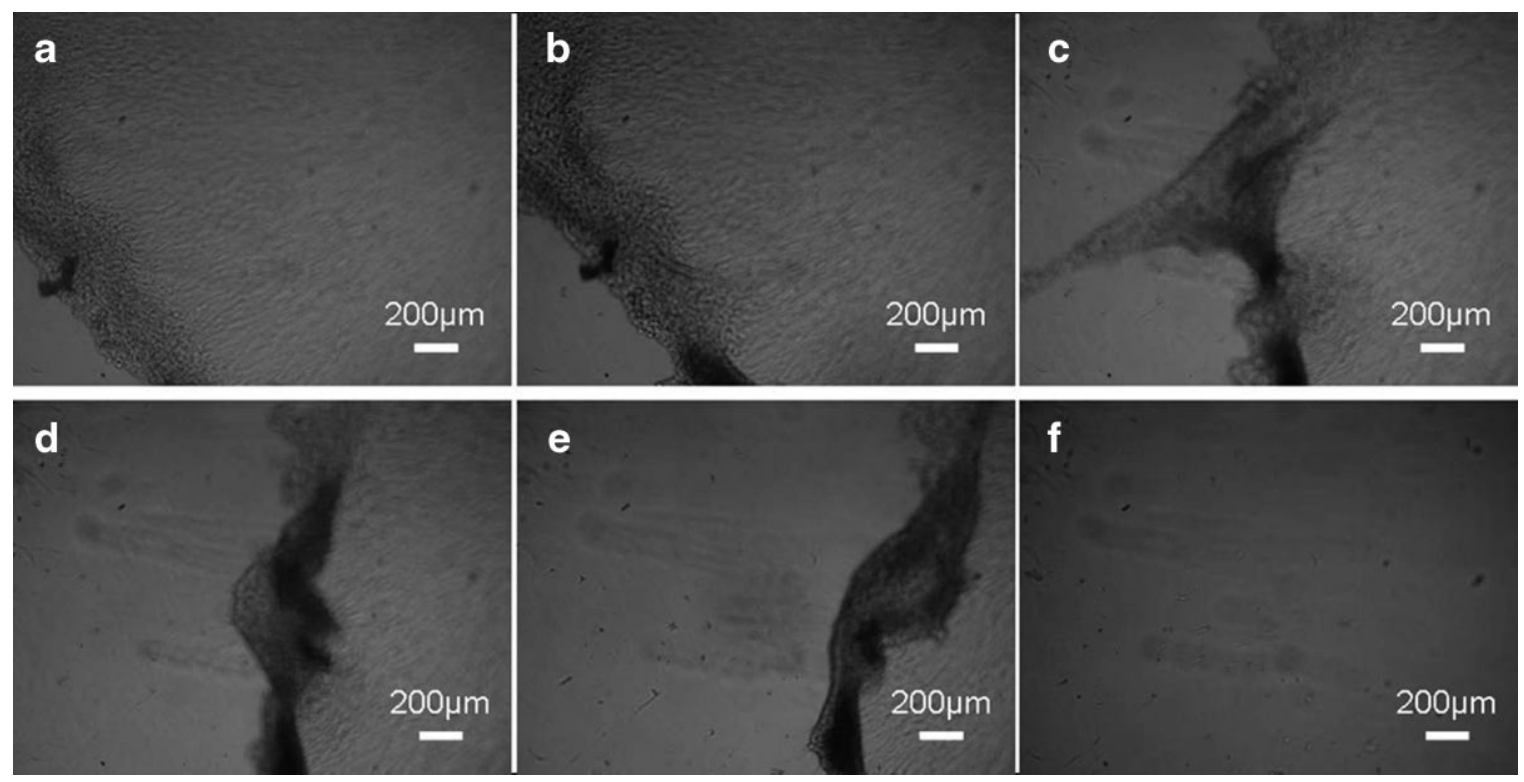

Figure 8. Light microscopy sequence (a-f) of the detachment, at room temperature (ca. $16^{\circ} \mathrm{C}$ ), of a confluent cell sheet grown on the PNIPAAm-grafted chitosan membranes (P-iPrOH75).

the amount of PNIPAAm in a superficial region of the membranes $(1-5 \mu \mathrm{m})$ by means of increasing the polymerization solvent swelling ratio. PNIPAAm was not detected in the ${ }^{1} \mathrm{H}$-NMR spectra of the samples modified at low (iPrOH90) and non-swelling conditions (iPrOH100), revealing that the modification occurs mainly at superficial level, as it would be expected. In turn, the grafting yield calculated by ${ }^{1} \mathrm{H}-\mathrm{NMR}$ is considerable high for $\mathrm{iPrOH} 75$ (5.3 wt.\%) and iPrOH50 (5.5 wt.\%), indicating a much deeper modification of these membranes. The XPS core level spectra for $\mathrm{C} 1 \mathrm{~s}$ and $\mathrm{O} 1 \mathrm{~s}$ show that PNIPAAm is grafted on the surface of non-swollen chitosan membranes (iPrOH100), in which chain entanglement is not an expected mechanism for PNIPAAm chains immobilization.

The immobilization of PNIPAAm chains on these membranes should take place by transfer reactions of the growing PNIPAAm radicals to the side substituents of the pyranosyl groups of chitosan. In the other samples (iPrOH50, iPrOH75, P-iPrOH75 and iPrOH90), polymer chains physical entanglement cannot be discharged as a concomitant mechanism for PNIPAAm immobilization.

The plasma-treated chitosan membranes grafted with PNIPAAm (P-iPrOH75) produced fully confluent viable cell sheets after 10 days of culture. The confluent cell sheets were harvested from the thermo-responsive chitosan membranes (P-iPrOH75) by lowering the temperature. Although it was not possible to reach $100 \%$ confluence on the other PNIPAAm modified chitosan membranes, we were able to observe the low temperature detachment of some single cells and smaller patches of confluent cells.
The use of chitosan membranes, which possess adequate permeation properties for the rapid elimination or delivery of small molecules (da Silva et al., accepted), would increase the mass transfer of nutrients and metabolic wastes, hopefully supporting the culture of thicker layered cell sheet constructs. Finally, fully hydrated chitosan membranes are flexible (Silva et al., 2004b) and they should be easily adaptable to several anatomical shapes, facilitating the transfer of either single cell sheets or layered cell sheet constructs directly to the host site with minimal manipulation.

This work was partially supported by the Portuguese Foundation for Science and Technology (FCT), through funds from the POCTI and/ or FEDER programs and through the scholarship SFRH/BD/6862/ 2001 granted to Ricardo M.P. da Silva. Paula M. López-Pérez acknowledges EU Marie Curie Actions, Alea Jacta EST (MEST-CT2004-008104) for providing her PhD Grant. This work was carried out under the scope of the European NoE EXPERTISSUES (NMP3-CT2004-500283) and also partially supported by the European Union funded STREP Project HIPPOCRATES (NMP3-CT-2003-505758).

\section{References}

Adem E, Avalos-Borja M, Bucio E, Burillo G, Castillon FF, Cota L. 2005. Surface characterization of binary grafting of AAc/NIPAAm onto poly(tetrafluoroethylene) (PTFE). Nucl Instrum Methods Phys Res Sect B: Beam Interact Mater Atoms 234(4):471-476.

Baran ET, Tuzlakoglu K, Salgado AJ, Reis RL. 2004. Multichannel mould processing of 3D structures from microporous coralline hydroxyapatite granules and chitosan support materials for guided tissue regeneration/ engineering. J Mater Sci Mater Med 15(2):161-165. 
Baysal BM, Karasz FE. 2003. Coil-globule collapse in flexible macromolecules. Macromol Theor Simul 12(9):627-646.

Briggs D. 1998. Surface analysis of polymers by XPS and static SIMS. Cambridge, UK: Cambridge University Press. pp. 47-87.

Bullett NA, Talib RA, Short RD, McArthur SL, Shard AG. 2006. Chemical and thermo-responsive characterisation of surfaces formed by plasma polymerisation of $\mathrm{N}$-isopropyl acrylamide. Surf Interface Anal 38(7):1109-1116.

Canavan HE, Cheng XH, Graham DJ, Ratner BD, Castner DG. 2005. Cell sheet detachment affects the extracellular matrix: A surface science study comparing thermal liftoff, enzymatic, and mechanical methods. J Biomed Mater Res Part A 75(1):1-13.

da Silva RMP, Mano JF, Reis RL. 2007. Smart thermoresponsive coatings and surfaces for tissue engineering: Switching cell-material boundaries. Trends Biotechnol 25(12):577-583.

da Silva RMP, Caridade SG, San Roman J, Mano JF, Reis RL. accepted. Transport of small anionic and neutral solutes through chitosan membranes: Dependence on crosslinking and chelation of divalent cations. Biomacromol.

da Silva RMP, Mano JF, Reis RL. 2008. Straightforward determination of the degree of $\mathrm{N}$-acetylation of chitosan by means of 1st derivative UV spectrophotometry. Macromol Chem Phys. DOI: 10.1002/ macp. 200800191.

Duracher D, Veyret R, Elaissari A, Pichot C. 2004. Adsorption of bovine serum albumin protein onto amino-containing thermosensitive coreshell latexes. Polym Int 53(5):618-626.

Elvira C, Mano JF, San Roman J, Reis RL. 2002. Starch-based biodegradable hydrogels with potential biomedical applications as drug delivery systems. Biomaterials 23(9):1955-1966.

Fujishige S, Kubota K, Ando I. 1989. Phase-transition of aqueoussolutions of poly( $\mathrm{N}$-isopropylacrylamide) and poly( $\mathrm{N}$-isopropylmethacrylamide). J Phys Chem US 93(8):3311-3313.

Graziano G. 2000. On the temperature-induced coil to globule transition of poly- $\mathrm{N}$-isopropylacrylamide in dilute aqueous solutions. Int J Biol Macromol 27(1):89-97.

Harimoto M, Yamato M, Hirose M, Takahashi C, Isoi Y, Kikuchi A, Okano T. 2002. Novel approach for achieving double-layered cell sheets co-culture: Overlaying endothelial cell sheets onto monolayer hepatocytes utilizing temperature-responsive culture dishes. J Biomed Mater Res 62(3):464-470.

Huber DL, Manginell RP, Samara MA, Kim BI, Bunker BC. 2003. Programmed adsorption and release of proteins in a microfluidic device. Science 301(5631):352-354.

Ide T, Nishida K, Yamato M, Sumide T, Utsumi M, Nozaki T, Kikuchi A, Okano T, Tano Y. 2006. Structural characterization of bioengineered human corneal endothelial cell sheets fabricated on temperatureresponsive culture dishes. Biomaterials 27(4):607-614.

Kikuchi A, Okano T. 2005. Nanostructured designs of biomedical materials: Applications of cell sheet engineering to functional regenerative tissues and organs. J Control Release 101(1-3):69-84.

Kim YS, Lim JY, Donahue HJ, Lowe TL. 2005. Thermoresponsive terpolymeric films applicable for osteoblastic cell growth and noninvasive cell sheet harvesting. Tissue Eng 11(1-2):30-40.

Kubota K, Fujishige S, Ando I. 1990. Single-chain transition of $\operatorname{poly}(\mathrm{N}$ isopropylacrylamide) in water. J Phys Chem US 94(12):5154-5158.

Kumar M. 2000. A review of chitin and chitosan applications. React Funct Polym 46(1):1-27.

Kwon OH, Kikuchi A, Yamato M, Sakurai Y, Okano T. 2000. Rapid cell sheet detachment from poly( $N$-isopropylacrylamide)-grafted porous cell culture membranes. J Biomed Mater Res 50(1):82-89.

Kwon OH, Kikuchi A, Yamato M, Okano T. 2003. Accelerated cell sheet recovery by co-grafting of PEG with PIPAAm onto porous cell culture membranes. Biomaterials 24(7):1223-1232.

Lopez-Perez PM, Marques AP, da Silva RMP, Pashkuleva I, Reis RL. 2007. Effect of chitosan membranes' surface modification via plasma induced polymerization on the adhesion of osteoblast-like cells. J Mater Chem 17(38):4064-4071.
Mano JF, Reis RL. 2007. Osteochondral defects: Present situation and tissue engineering approaches. J Tissue Eng Regen Med 1(4):261-273.

Mayo FR. 1943. Chain transfer in the polymerization of styrene: The reaction of solvents with free radicals. J Am Chem Soc 65(12):23242329.

Murakami D, Yamato M, Nishida K, Ohki T, Takagi R, Yang J, Namiki H, Okano T. 2006a. The effect of micropores in the surface of temperature- responsive culture inserts on the fabrication of transplantable canine oral mucosal epithelial cell sheets. Biomaterials 27(32):55185523.

Murakami D, Yamato M, Nishida K, Ohki T, Takagi R, Yang J, Namiki H, Okano T. 2006b. Fabrication of transplantable human oral mucosal epithelial cell sheets using temperature-responsive culture inserts without feeder layer cells. J Artif Organs 9(3):185-191.

Nakajima K, Honda S, Nakamura Y, Lopez-Redondo F, Kohsaka S, Yamato M, Kikuchi A, Okano T. 2001. Intact microglia are cultured and non-invasively harvested without pathological activation using a novel cultured cell recovery method. Biomaterials 22(11):12131223.

Nishida K, Yamato M, Hayashida Y, Watanabe K, Yamamoto K, Adachi E, Nagai S, Kikuchi A, Maeda N, Watanabe H, et al. 2004. Corneal reconstruction with tissue-engineered cell sheets composed of autologous oral mucosal epithelium. N Engl J Med 351(12):1187-1196.

Okaya T, Fujita H, Suzuki A, Kikuchi K. 2004. Study on chain transfer reaction of poly(vinyl acetate) radical with poly(vinyl alcohol) in a homogeneous system. Des Monomers Polym 7(3):269.

Patel M, Mao L, Wu B, VandeVord PJ. 2007. GDNF-chitosan blended nerve guides: A functional study. J Tissue Eng Regen Med 1(5):360367.

Prabaharan M, Mano JF. 2005. Chitosan-based particles as controlled drug delivery systems. Drug Deliv 12(1):41-57.

Ratner BD. 1996. Surface properties of materials. In: Ratner BD, Hoffman AS, Schoen FJ, Lemons JE, editors. Biomaterials Science: An introduction to Materials in Medicine. San Diego: Academic Press. pp. 2135.

Scarpa JS, Mueller DD, Klotz IM. 1967. Slow hydrogen-deuterium exchange in a non-alfa-helical polyamide. J Am Chem Soc 89(24): 6024-6030.

Shimizu T, Yamato M, Kikuchi A, Okano T. 2001. Two-dimensional manipulation of cardiac myocyte sheets utilizing temperature-responsive culture dishes augments the pulsatile amplitude. Tissue Eng 7(2):141-151.

Shimizu T, Yamato M, Isoi Y, Akutsu T, Setomaru T, Abe K, Kikuchi A, Umezu M, Okano T. 2002. Fabrication of pulsatile cardiac tissue grafts using a novel 3-dimensional cell sheet manipulation technique and temperature-responsive cell culture surfaces. Circ Res 90(3):E40-E48.

Shimizu T, Yamato M, Kikuchi A, Okano T. 2003. Cell sheet engineering for myocardial tissue reconstruction. Biomaterials 24(13):23092316.

Siddaramaiah, Kumar P, Divya KH, Mhemavathi BT, Manjula DS. 2006. Chitosan/HPMC polymer blends for developing transdermal drug delivery systems. J Macromol Sci Part A: Pure Appl Chem A43(3): 601-607.

Silva RM, Elvira C, Mano JF, San Roman J, Reis RL. 2004a. Influence of beta-radiation sterilisation in properties of new chitosan/soybean protein isolate membranes for guided bone regeneration. J Mater Sci Mater Med 15(4):523-528.

Silva RM, Silva GA, Coutinho OP, Mano JF, Reis RL. 2004b. Preparation and characterisation in simulated body conditions of glutaraldehyde crosslinked chitosan membranes. J Mater Sci Mater Med 15(10):11051112 .

Silva GA, Ducheyne P, Reis RL. 2007. Materials in particulate form for tissue engineering. 1. Basic concepts. J Tissue Eng Regen Med 1(1):424.

Terbojevich M, Cosani A, Muzzarelli RAA. 1996. Molecular parameters of chitosans depolymerized with the aid of papain. Carbohydr Polym 29(1):63-68. 
Thacharodi D, Panduranga Rao K. 1996. Rate-controlling biopolymer membranes as transdermal delivery systems for nifedipine: Development and in vitro evaluations. Biomaterials 17(13):1307.

Tuzlakoglu K, Alves CM, Mano JF, Reis RL. 2004. Production and characterization of chitosan fibers and 3-D fiber mesh scaffolds for tissue engineering applications. Macromol Biosci 4(8):8118819.

Von Recum HA, Okano T, Kim SW, Bernstein PS. 1999. Maintenance of retinoid metabolism in human retinal pigment epithelium cell culture. Exp Eye Res 69(1):97-107.

Wang C, Ye W, Zheng Y, Liu X, Tong Z. 2007. Fabrication of drug-loaded biodegradable microcapsules for controlled release by combination of solvent evaporation and layer-by-layer self-assembly. Int J Pharm 338(1-2):165-173.

Yamada N, Okano T, Sakai H, Karikusa F, Sawasaki Y, Sakurai Y. 1990. Thermoresponsive polymeric surfaces-Control of attachment and detachment of cultured-cells. Makromol Chem Rapid 11(11): 571-576.

Yamato M, Konno C, Kushida A, Hirose M, Utsumi M, Kikuchi A, Okano T. 2000. Release of adsorbed fibronectin from temperatureresponsive culture surfaces requires cellular activity. Biomaterials 21(10):981-986.

Yamato M, Utsumi M, Kushida A, Konno C, Kikuchi A, Okano T. 2001. Thermo-responsive culture dishes allow the intact harvest of multilayered keratinocyte sheets without dispase by reducing temperature. Tissue Eng 7(4):473-480.

Yang J, Yamato M, Kohno C, Nishimoto A, Sekine H, Fukai F, Okano T. 2005. Cell sheet engineering: Recreating tissues without biodegradable scaffolds. Biomaterials 26(33):6415-6422.

Zhu X, Chian KS, Chan-Park MBE, Lee ST. 2005. Effect of argon-plasma treatment on proliferation of human-skin-derived fibroblast on chitosan membrane in vitro. J Biomed Mater Res Part A 73(3):264-274. 